\title{
Huxie Huaji Ointment Induced Apoptosis of Liver Cancer Cells In Vivo and In Vitro by Activating the Mitochondrial Pathway
}

\author{
Yuan Cai $\mathbb{D}^{1},{ }^{1}$ Qing Du $\mathbb{D}^{1},{ }^{1}$ Tian-Hao Deng $\mathbb{D}{ }^{1}{ }^{1}$ Bing-Bing Shen $\mathbb{D}^{1},{ }^{1}$ Yan-Mei Peng $\mathbb{D},{ }^{1}$ \\ Pu-Hua Zeng $\mathbb{D}{ }^{1}$, and Song-Ren Yu $\mathbb{D}^{2}$ \\ ${ }^{1}$ Institute of Traditional Chinese Medicine, Hunan Academy of Chinese Medicine, Changsha 410006, China \\ ${ }^{2}$ Jiangxi University of Chinese Medicine, Nanchang, Jiangxi 330006, China \\ Correspondence should be addressed to Pu-Hua Zeng; 282638728@qq.com and Song-Ren Yu; 48877086@qq.com
}

Received 9 March 2021; Revised 28 May 2021; Accepted 6 July 2021; Published 15 July 2021

Academic Editor: Yu CAI

Copyright (c) 2021 Yuan Cai et al. This is an open access article distributed under the Creative Commons Attribution License, which permits unrestricted use, distribution, and reproduction in any medium, provided the original work is properly cited.

Huxie Huaji (HXHJ) Ointment is a famous traditional Chinese medicinal prescription and is commonly used for the clinical treatment of hepatocellular carcinoma by boosting immunity and detoxification. However, the scientific evidence for the effect of $\mathrm{HXHJ}$ Ointment on hepatocellular carcinoma and the underlying molecular mechanism are lacking. The present study aimed to identify the effects of HXHJ Ointment on hepatocellular carcinoma in vitro and in vivo as well as investigating the mechanistic basis for the anticancer effect of HXHJ ointment. First, liquid chromatography-mass spectrometry was used to verify the composition of HXHJ Ointment and quality control. Second, in vitro, Cell Counting Kit (CCK8) cell viability assay and Hoechst 33342 staining assay were performed to explain the cell apoptosis. The protein levels of tumor suppressor protein ( $p 53)$, B-cell lymphoma 2 gene (Bcl-2), cytochrome C (Cyt-C), and aspartate proteolytic enzyme-3 (caspase-3) were examined by immunofluorescence. Finally, in vivo, hematoxylin and eosin (H\&E) staining was used to observe the pathological changes in hepatocellular carcinoma samples. Western blots and immunohistochemistry were used to detect the anticancer properties of HXHJ ointment. The results in vitro showed that $20 \% \mathrm{HXHJ}$ Ointment serum could significantly inhibit HepG2 cell proliferation, increased tumor suppressor gene $p 53$, downregulated antiapoptotic protein $\mathrm{Bcl}-2$, promoted the release of mitochondrial Cyt-C, activated caspase-3, and induced HepG2 cell apoptosis. Furthermore, in vivo experiments showed that HXHJ Ointment could effectively inhibit tumor growth in nude mice xenotransplanted with HepG2 cells, changed the morphology of tumor cells, and regulated the expression of apoptosis-related protein pathway $p 53 / \mathrm{Bcl}-2 / \mathrm{Cyt}-\mathrm{C} /$ caspase- 3 . HXHJ Ointment can significantly inhibit the development of hepatocellular carcinoma, and its mechanism may be related to the regulation of $p 53 / \mathrm{Bcl}-2 / \mathrm{Cyt}-\mathrm{C} /$ caspase-3 signaling pathway to induce cell mitochondrial apoptosis.

\section{Introduction}

Hepatocellular carcinoma (HCC) is a more common malignancy than the majority of cancers and ranks second in the world's top causes of cancer-related mortality [1]. Progress has been made in the diagnosis and therapy and we are encouraged by the recent success, while survival benefits remain modest due to the difficulty in being diagnosed early and the disease progressing quickly [2]. Currently, the major clinical treatment strategies for HCC include surgery, radiotherapy, and chemotherapy [3]. Unfortunately, radiotherapy and chemotherapy are not suitable for everyone and have the drawbacks of "kill a thousand enemies, hurt yourself eight hundred." Moreover, those who have undergone hepatectomy or liver transplantation are frequently subject to survival declines due to recurrence and metastasis [4]. Thus, there is an urgent need for more effective treatment to reduce the rate of recurrence and metastasis, relieve clinical symptoms of HCC, and improve long-term patient survival and high quality of life.

Studies on looking for the new drugs that can kill tumor cells and enhance the body's immunity may provide insight into novel therapeutic strategies. Traditional Chinese medicine (TCM), especially the formulas, has been used 
clinically for more than five thousand years in China and Asia. Various studies have shown that traditional Chinese medicine formulas (TCMF) have a marked effect on the treatment of liver cancer [5]. With an overall concept, it has a unique therapeutic effect and fewer side effects on HCC patients. It can not only inhibit tumor growth but also alleviate patients' clinical symptoms and improve their quality of life [6].

Apoptosis is one such cell death pathway which allows a damaged or stressed cell to deconstruct in a regulated manner without causing inflammation and has garnered much attention in the cancer field, with hopes of eliminating malignant cells through its activation. Accumulating evidence has suggested that the mitochondrial pathway of apoptosis in a cell is one of the most important hallmarks of HCC $[7,8]$. In mammals, activation of caspases is under the tight control of the Bcl-2 family proteins, named in reference to the first discovered mammalian cell death regulator $[9,10]$. These proteins mainly act by regulating the release of caspases activators from mitochondria. Mitochondria appear today as the central executioner of apoptosis. Cyt-C is one of the apoptotic factors released by mitochondria into the cytoplasm and can bind to Apaf-1 (apoptosis protease activating factor) and induce cell apoptosis. The $p 53$ tumor suppressor protein plays a central role in the regulation of apoptosis. Thus, documentation of changes to the expression of these markers would provide insights as to the mechanism whereby TCMF might be of value in the treatment of HCC.

Huxie Huaji (HXHJ) Ointment is a classic anticancer prescription and clinical studies have shown that HXHJ Ointment can improve patient quality of life and extend survival time when used to treat advanced primary liver cancer. It can significantly enhance the therapeutic effect and reduce tumor resistance in combination with Western Medicine chemotherapy. In our previous study, we found that HXHJ Ointment could significantly inhibit the proliferation of $\mathrm{H}_{22}$ cells by inducing the imbalance of the expression ratio of $\mathrm{Bax}$ and $\mathrm{Bcl}-2$ proteins in vitro [11]. In the current study, our aim was to confirm the effects of HXHJ Ointment on HepG2 cells and tumor growth. Elucidation of the apoptosis mechanisms and molecular biology in HCC underlying $\mathrm{HXHJ}$ Ointment will provide more comprehensive and precise insight into clinical guidance.

\section{Materials and Methods}

2.1. Materials. Huxie Huaji (HXHJ) Ointment was made up of ten herbs, Codonopsis Radix, Astragali Radix, Herba Hedyotidis Diffusae, Agrimonia pilosa Ledeb., Scutellaria barbata D. Don., Reynoutria japonica Houtt., Smilax china L., Fructus Ligustri Lucidi, Buthus martensii Karsch, and Gekko swinhonis Guenther in the proportion $20: 30: 15: 15$ : $10: 10: 5: 3: 2: 2$. All the crude drugs were obtained from the Affiliated Hospital of Hunan Academy of Traditional Chinese Medicine (Changsha, China). The voucher specimens were stored in the Herbal Medicine Room (Institute of Traditional Chinese Medicine, Hunan Academy of Traditional Chinese Medicine, Changsha). Cisplatin injection was purchased from Baxter International Co., Ltd. (Illinois, USA), with batch number 8H259A.

The CCK8 kit was purchased from Shanghai Qihai Biomedical Technology Co., Ltd. (Shanghai, China). DMEM/F12 medium and fetal bovine serum (FBS) were purchased from Gibco (New York, USA). Nuclear dye Hoechst 33258 and DAPI were purchased from Solarbio (Beijing, China). Bcl-2, caspase-3, Cyt-C, and $p 53$ primary antibodies were purchased from Proteintech (Wuhan, China). GAPDH was purchased from ImmunoWay (New York, USA). Phosphodiesterase inhibitor, goat anti-mouse secondary antibody, and goat anti-rabbit secondary antibody were purchased from Auragene (Changsha, China). $\mathrm{DAB}$ color reagent kit was purchased from Beijing Zhongshan Jinqiao Biotechnology Co., Ltd. (Beijing, China).

\subsection{HXHJ Sample Preparation and Quality Control by Using HPLC and HPLC-Q-TOF}

2.2.1. HXHJ Sample Preparation. According to the Chinese Pharmacopoeia (2015 edition), the HXHJ sample mixture was immersed in deionized water (6 times its total weight) overnight. Subsequently, they were decocted for 1 hour for the first time. Then, the extraction was repeated by adding deionized water (4 times its weight) and boiled for 1 hour. Finally, the two extracts were mixed. A part of the extract was concentrated and centrifuged to an appropriate concentration for HPLC-MS analysis, and the remaining part was freeze-dried for further use. The final amount of the extracted HXHJ powder was $230.34 \mathrm{~g}$ (yield, $14.28 \%(\mathrm{w} / \mathrm{w})$ )). The main pharmacologically active ingredients are known (Figure 1).

2.2.2. HPLC Conditions. The chromatography analytical procedures were performed on an Agilent 1260 HPLC system (Agilent Technologies, Santa Clara, CA, USA). Chromatographic separation was performed on an Agilent Eclipse XDB-C18 column $(4.6 \times 250 \mathrm{~mm}, 5 \mu \mathrm{m})$. The mobile phase consisted of A ( $0.1 \%$ formic acid in water) and $\mathrm{B}$ (Acetonitrile) was programmed as follows: $0-5 \mathrm{~min}, 5-10 \%$ B; 5-25 min, $10-45 \%$ B; $25-40 \mathrm{~min}, 45-65 \% \mathrm{~B}$; and 40-65 min, $65-100 \% \mathrm{~B}$. The flow rate was $1 \mathrm{~mL} / \mathrm{min}$ while the column temperature was set at $30^{\circ} \mathrm{C}$. Spectra were recorded from 190 to $400 \mathrm{~nm}$, while the chromatogram was acquired at $330 \mathrm{~nm}$.

2.2.3. Mass Spectrometry Conditions. Agilent 6530 Accurate-Mass Q-TOF LC/MS system (Agilent Technologies, Santa Clara, CA) was equipped with an electrospray ionization (ESI); MS data were acquired across the range $\mathrm{m} / \mathrm{z}$ $100-1500$ in positive and negative ion modes. The operating conditions were as follows: nitrogen as dry gas with temperature at $325^{\circ} \mathrm{C}$ and flow rate at $5.0 \mathrm{~L} / \mathrm{min}$, and sheath gas with temperature at $400^{\circ} \mathrm{C}$ and flow rate at $12 \mathrm{~L} / \mathrm{min}$; pressure of nebulizer, 55 psi; capillary voltage, $3500 \mathrm{~V}$; skimmer, $65 \mathrm{~V}$; OCT $1 \mathrm{RF} \mathrm{Vpp}, 750 \mathrm{~V}$; and fragmentor voltage, $130 \mathrm{~V}$. The mass axis was calibrated using the 


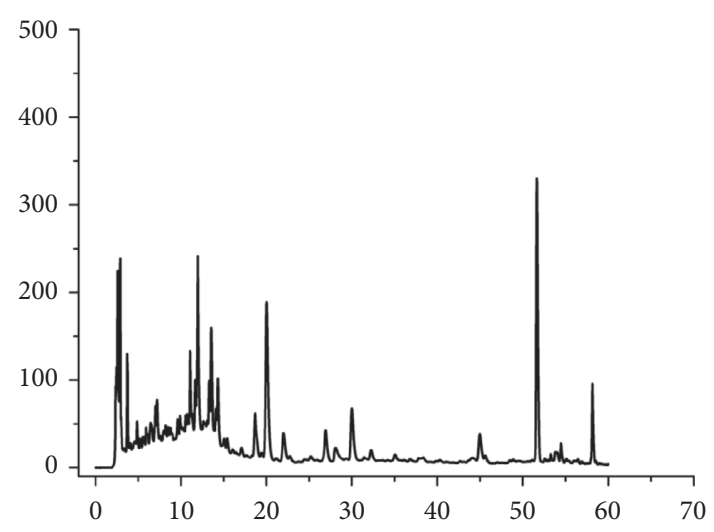

(a)

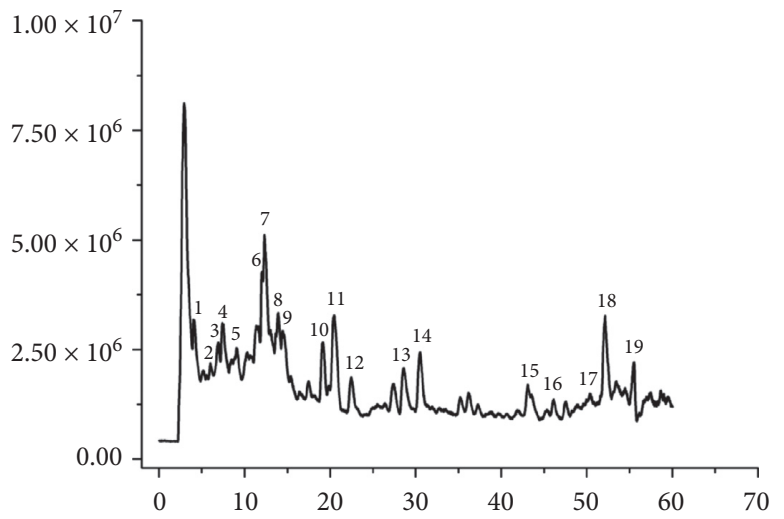

(b)

FIgURE 1: Representative HPLC chromatograms (a) and mass spectrum ESI (-) chromatograms (b) of HXHJ.

mixture. For full scan MS analysis, the spectra were recorded in the range of $\mathrm{m} / \mathrm{z} 70-3200$. All operations, acquisition, and analysis of data were monitored by Agilent HPLC-ESI-QTOF-MS MassHunter Acquisition Software version A.01.00 and operated under MassHunter Acquisition Software Version B.05.00.

2.3. Preparation of HXHJ-Medicated Serum. Adult Sprague Dawley rats (180-200 g) were purchased from Hunan Slack Jingda Experimental Animal Co., Ltd. The rats were kept in cages under the conditions of a light/dark cycle of $12 \mathrm{~h} / 12 \mathrm{~h}$ (lighting time $7: 00-19: 00$ ), and they have free access to feed and water. This study was approved and conducted by the animal ethics committee of Hunan Academy of Chinese Medicine (approval number: 20200025). All procedures were performed in accordance with the Guidance Suggestions for the Care and Use of Laboratory Animals, formulated by the Ministry of Science and Technology of China.

20 rats were randomly divided into HXHJ group $(n=10)$ and control group $(n=10)$. The HXHJ group was treated by intragastric administration of HXHJ $(2.44 \mathrm{~g} / \mathrm{kg})$ twice a day for 3 days. One hour following the final administration, the blood sample was collected from the abdominal aorta and centrifuged $(3000 \times \mathrm{g}, 15 \mathrm{~min})$. The $\mathrm{HXHJ}$-medicated serum was inactivated by heating $\left(56^{\circ} \mathrm{C}, 30 \mathrm{~min}\right)$, filtered through a $0.22 \mu \mathrm{m}$ filter, and stored at $-80^{\circ} \mathrm{C}$. Rats in the control group took purified water orally with the same protocol to prepare blank serum.

2.4. Cell Culture and Treatment. Human hepatocellular carcinoma (HepG2) cells were obtained from the China Center for Type Culture Collection (CCTCC, Wuhan, China). The cells were grown in sterile plastic flasks or plates in DMEM medium supplemented with $10 \%$ fetal bovine serum (FBS), $10 \mu \mathrm{l} / \mathrm{mL}$ penicillin-streptomycin solution, and incubated at $37^{\circ} \mathrm{C}, 5 \% \mathrm{CO}_{2}$ in a humidified atmosphere. The cells were then treated separately with serum containing $\mathrm{HXHJ}$ of different solubility and cisplatin (positive control).
Cells were collected at different time points according to experiment requirements.

2.5. Cell Counting Kit. The effect of serum containing HXHJ on the proliferation of HepG 2 cells was evaluated by CCK- 8 assay. Cells were seeded into 96-well culture plates at a density of $1 \times 10^{3}$ cells/well and incubated in a complete medium overnight. Cells were then cultured in $100 \mu \mathrm{L}$ of fresh medium containing various concentrations of the medicated serum $(5 \%, 10 \%, 15 \%$, and $20 \%)$ and cisplatin $(12.5,25,50$, and $100 \mu \mathrm{mol} / \mathrm{L})$ for $24 \mathrm{~h}$. Next, $20 \mu \mathrm{L}$ CCK-8 stock solution was added to each well for $4 \mathrm{~h}$. Finally, a multifunctional microplate reader (Thermo, USA) was used to measure the OD value of each well at $450 \mathrm{~nm}$ wavelength and calculate the cell inhibition rate of each group.

2.6. HepG2 Cell Morphology Observation. The cells were seeded into a 24-well culture plate at a density of $2 \times 10^{4}$ cells/well and incubated overnight in a complete medium. The cells were randomly divided into a normal control group, $20 \%$ blank serum group, $100 \mu \mathrm{mol} / \mathrm{L}$ cisplatin group, and $20 \% \mathrm{HXHJ}$ drug-containing serum group. The morphological changes of each group were observed on an inverted microscope (OLYMPUS, Japan).

2.7. Hoechst Staining. To examine cell apoptosis, the Hoechst 33342 staining assay was performed as previously reported [12] with minor revision. HepG2 cells were seeded into 6-well plates for $12 \mathrm{~h}$ and then treated with different concentrations of PE for $24 \mathrm{~h}$. Subsequently, the culture medium was removed and the HepG2 cells were stained with Hoechst 33342 (final concentration $1.0 \mathrm{mg} / \mathrm{mL}$ ) for $20 \mathrm{~min}$, the apoptotic cell changes in morphology such as chromatin condensation and nuclear shrinking could be characterized. The fluorescence was observed under a fluorescence microscope and images were captured with an electronic camera (Olympus, Tokyo; 100 magnification). 
2.8. TUNEL Staining. Take the logarithmic growth phase cells, inoculate them in a black 96-well culture plate $\left(1 \times 10^{5}\right.$ per well), and culture them for $24 \mathrm{~h}$. First, HepG2 cells were fixed with $4 \%$ cell fixative solution for $45 \mathrm{~min}$, then $0.25 \%$ Triton-100 was added dropwise for $15 \mathrm{~min}$ and then treated with $3 \% \mathrm{H}_{2} \mathrm{O}_{2}$ for $2 \mathrm{~min}$. Second, the preprepared tunel reaction mixture $(50 \mu \mathrm{l} \mathrm{TdT}+450 \mu \mathrm{l}$ fluorescein-labeled dUTP) was added and incubated for $1 \mathrm{~h}$ in a humid chamber at $37^{\circ} \mathrm{C}$ in the dark. Third, DAPI working solution $(100 \mathrm{~g} / \mathrm{L})$ was added to each well and incubated at room temperature for $15 \mathrm{~min}$ in the dark. Finally, the cell apoptosis under a laser confocal microscope was observed (Olympus, Tokyo; 100 magnification). Apoptosis rate/\% = number of apoptotic cells/total number of cells $\times 100 \%$, and the average value was used as an index of apoptosis.

2.9. Immunofluorescence Analysis. HepG2 cells were inoculated into PE black 96-well cell culture plate and fixed with $4 \%$ paraformaldehyde for $45 \mathrm{~min}, 0.25 \%$ Triton-100 for $15 \mathrm{~min}$, and 5\% BSA for $10 \mathrm{~min}$. Rabbit anti-human Cyt-C, p53, Bcl-2, caspase-3, and primary antibody dilution $(1: 100)$ were added to the cell culture plate and incubated at $4^{\circ} \mathrm{C}$ overnight. FITC-labeled goat anti-rabbit secondary antibody dilution (1:400) was added, the liquid was discarded, the DAPI diluent $(1: 800)$ was added and incubated in dark at room temperature for $15 \mathrm{~min}$. Protein fluorescence intensity was analyzed and processed using the OPERETTA type HCA (PerkinElmer, Massachusetts, USA) and each group of the randomly selected five horizons. The first DAPI labeled nuclei were circled, and FITC-labeled positive expression cells were found. The total fluorescence intensity value of the positive cells was calculated.

2.10. Establishment of Mouse Tumor Model. This research was reviewed and approved by the Experimental Animal Welfare Ethics Committee of Hunan An-sheng-mei Animal Research Institute (approval number: ASM2019043). The design and plan fully considered the principles of safety and fairness. Four-week-old female BALB/c nu/nu mice $(15-20 \mathrm{~g})$ were maintained in a specific pathogen-free environment. After 2 weeks of adaptation, the mice were injected subcutaneously in the right armpit with $0.2 \mathrm{~mL}$ HepG2 cells $\left(2 \times 10^{7} / \mathrm{mL}\right)$ and then randomized into treatment groups as follows: model group (saline, $n=6$ ), cisplatin group ( $4 \mathrm{mg} / \mathrm{kg}, n=6)$, and HXHJ-treated group ( $1 \mathrm{mg} / \mathrm{kg}$, $n=6)$. The mice in the model control (normal saline) and $\mathrm{HXHJ}$-treated group received intragastric administration (i.g.) every day. The mice in the positive groups receive an intraperitoneal injection (i.p.) every three days.

2.11. Tumor Volume and Weight Determination. Body weights and tumor volumes were measured every two days with daily general observations. Tumor growth was monitored by a digital Vernier, $V=\left(a \times b^{2}\right) / 2\left(\mathrm{~cm}^{3}\right)(a$ : tumor long diameter, $b$ : tumor short diameter) to construct the growth curves. After the experiment, blood was taken from the heart of the mouse and then it was euthanized; the tumor tissue was excised and weighed. The tumor inhibition rate (IR) of each group was calculated by the formula, IR $=(1-$ experimental group tumor weight/control group tumor weight) $\times 100 \%$. A portion of tumor tissue was fixed in $4 \%$ paraformaldehyde and the remaining tissue was stored in liquid nitrogen.

\subsection{Hematoxylin and Eosin (H\&E) Staining.} Hematoxylin and eosin (H\&E) staining and optical microscope (TEM) analysis were used to evaluate histopathological characteristics of xenografts performed as the previous description reported [13]. Briefly, the tumor tissues were fixed with $4 \%$ paraformaldehyde, embedded in paraffin, while being fixed in $2.5 \%$ glutaraldehyde and $1 \%$ osmic acid, sectioned at $5 \mu \mathrm{m}$, stained with hematoxylin and eosin, and observed and photographed under 10x and 40x eyepieces under an optical microscope (Olympus, Tokyo, Japan).

2.13. Western Blotting Analysis. Protein expression of Bcl-2, caspase-3, Cyt-C, and p53 was detected using western blotting. Samples were washed with PBS and the appropriate amount of cell lysates was added. The tumor tissues were shaken at $4^{\circ} \mathrm{C}$ for $5 \mathrm{~min}$ and centrifuged at $4^{\circ} \mathrm{C}$ for $10 \mathrm{~min}$ $(10000 \times \mathrm{g})$. The supernatant was collected and protein was extracted. $50 \mu \mathrm{g}$ protein was conducted using SDS-PAGE and was transferred to a nitrocellulose filter (NC filter). After sealing with $5 \%$ BSA solution, polyclonal rabbit anti-mouse antibodies Bcl-2 (1:1000), caspase-3 (1:1000), Cyt-C (1: $500)$, and $p 53(1: 1000)$ were added to the protein and incubated overnight. TBST was used to wash the membrane 4 times. The membrane was then incubated in goat anti-rabbit IgG secondary antibody and rat anti-mouse secondary antibody (dilution at a $1: 2000$, Cell Signaling Technology) at $37^{\circ} \mathrm{C}$ for $1.5 \mathrm{~h}$ and detected with ECL kit (Pierce, MA, USA). Protein bands were analyzed and processed using ChemiDoc type gel imaging system (Bio-Rad, CA, USA).

2.14. Immunohistochemistry (IHC) Staining. The expression of Bcl-2, caspase-3, Cyt-C, and p53 was measured with immunohistochemistry. Tumor tissue was fixed with $10 \%$ neutral formaldehyde solution, paraffin-embedded, and cut into $4 \mu \mathrm{m}$ samples. Additional sections were deparaffinized through a graded series of dimethylbenzene and ethanol; tissue sections were washed gently with phosphate buffer saline, followed by incubation overnight at $4^{\circ} \mathrm{C}$ in solution with the Bcl-2 (1:500), Cyt-C (1:500), p53 (1:500), and caspase-3 $(1: 300)$ polyclonal rabbit anti-mouse antibodies (Proteintech, Wuhan, China), respectively. After washing, the sections were incubated with goat anti-rabbit IgG antibody (ab6721, 1:500 in PBS) for $50 \mathrm{~min}$ at room temperature. The sections were then washed again, incubated with 3,3-diaminobenzidine (Solarbio, DA1010), washed, and counterstained with hematoxylin. Five visual fields were selected randomly in each section and observed with a biological imaging microscope (Olympus, Tokyo, Japan) at 400x. The average optical density (AOD) was calculated. 
2.15. Statistical Analysis. Statistical analysis was performed on SPSS 22.0 software (Chicago, IL, USA). The results were expressed as mean \pm standard deviation (SD), and one-way ANOVA was used to company the results (GraphPad Prism 5.0, GraphPad Software, USA). $p<0.05$ indicated that there are significant differences.

\section{Results}

3.1. Quality Control and Identification of HXHJ. The chemical constituents of the HXHJ sample were analyzed by HPLC-ESI-QTOF-MS/MS in the positive and negative ionization modes. In the full scan mass spectra, the identified compounds are mainly exhibited in the form of $[\mathrm{M}-\mathrm{H}]^{-}$. The UV and total ions chromatogram of ESI(-) are shown in Figure 1. The retention time, molecular formula, name, and source of 19 compounds are summarized in Table 1. Among them, the contents of apigetrin, apigenin, and aloe emodin were $23.6 \%, 9.5 \%$, and $24.3 \%$, respectively. To ensure the quality of the HXHJ used in this study, apigetrin, apigenin, and aloe emodin were used as quality control standards.

\subsection{HXHJ-Medicated Serum Induced the Proliferation and} Morphological Changes of HepG2 Cells In Vitro. In order to know the cytotoxicity of HXHJ, we used the CCK8 method to detect the anti-HepG2 cell proliferation effect of HXHJcontaining serum and found that the blank serum had basically no effect on the proliferation of HepG2 cells. The $20 \% \mathrm{HXHJ}$-containing serum had the best anti-HepG2 cell proliferation effect. The inhibition rate was 39.15\% $(p<0.01)$ (Figure 2(a)). Taking $100 \mu \mathrm{mol} / \mathrm{L}$ cisplatin as a positive control, the effect trend of $100 \mu \mathrm{mol} / \mathrm{L}$ cisplatin and $20 \%$ $\mathrm{HXHJ}$-containing serum is the same compared with the normal group and blank group, and the changes in cell morphology were observed. It was found that, compared with the blank serum group, HXHJ-containing serum reduced cellular adhesiveness, fuzzy cellular structure, and cellular number (Figures 2(b) and 2(c)). These results suggest that $\mathrm{HXHJ}$ can effectively inhibit the proliferation of HepG2 cells and cause morphological changes.

\subsection{HXHJ-Medicated Serum Induces Apoptosis of HepG2 Cells} In Vitro. In order to further evaluate the mechanism of HXHJ-medicated serum inhibiting the proliferation of HepG2 cells, we also detected cell apoptosis by Hoechst staining (Figure 3(a)) and TUNEL staining (Figure 3(b)). Compared with the blank serum group, we found that HepG2 cell nuclei appeared densely stained when they are treated with $20 \% \mathrm{HXHJ}$-medicated serum. The nuclei were on one side; some of them emitted strong blue-white fluorescence and even nuclear fragmentation and other typical apoptosis features. The number of TUNEL positive cells and the positive cell rate increased significantly $(p<0.01)$. So, we speculated that HXHJ-medicated serum inhibits cell proliferation mainly due to the induction of cell apoptosis.
3.4. HXHJ Inhibits Tumor Growth in Nude Mice with HepG2 Xenograft Tumors In Vivo. In order to verify the antitumor effect of HXHJ in vitro and in vivo, the HepG2 xenograft tumor nude mouse model was employed to examine the effect of HXHJ in HCC. As the experimental cycle progressed, the weight of the tumor-bearing mice decreased. The weight loss of the positive drug group was the most significant. The weight loss trend of the HXHJ administration group was gentle, and the weight loss was less than that of the model group and the positive administration group (Figure 4(a)). Tumor weight and volume were significantly suppressed after HXHJ administration $(p<0.05)$, and the tumor inhibition rate was $41.07 \%$ (Figures $4(\mathrm{~b})$ and $4(\mathrm{c})$ ). Observed under an optical microscope, it was found that most of the cancer cells in the model group had irregular shapes, rich cytoplasm, and typical malignant tumor cell morphology, with large areas of cell-free eosinophilic staining. After HXHJ treatment, most tumor cells ruptured, the nuclei were pyknotic and deeply stained, and cell apoptosis appeared (Figure 4(d)).

3.5. HXHJ Regulated the Expression of Apoptosis-Related Protein Pathway p53/Bcl-2/Cyt-C/Caspase-3 In Vivo and In Vitro. To further explore the mechanism of HXHJ-induced apoptosis in hepatocellular carcinoma, we also detected the expression of apoptosis-related protein pathway p53/Bcl-2/ Cyt-C/caspase-3. Among them, Cyt-C efflux was the core process of mitochondrial apoptosis pathway; $p 53$ could downregulate the expression of antiapoptotic protein $\mathrm{Bcl}-2$, induce the release of apoptosis-forming factor Cyt-C, and recruit and activate caspase-3, thereby promoting cell apoptosis. In in vitro experiments, we used immunofluorescence to detect the expression of apoptosis-related proteins. The fluorescence intensity and localization of each protein were observed under a laser confocal microscope, and it was found that, in intervention treatment with 20\% HXHJcontaining serum, the relative fluorescence intensity of Bcl-2 in HepG2 cells was significantly reduced, and the relative fluorescence intensity of caspase-3, Cyt-C, and p53 was significantly increased $(p<0.01$, Figure $5(\mathrm{a}))$. In in vivo experiments, both western blotting (Figure 5(b)) and immunohistochemistry (Figure 5(c)) were used to quantitatively and qualitatively detect apoptosis-related proteins. It is found that the change trend of the integral optical density value and relative protein gray value of each protein was consistent with the in vitro study. Therefore, we speculate that the mechanism by which HXHJ induces hepatocellular carcinoma apoptosis and hinders its proliferation may be related to the regulation of the expression of mitochondrial apoptosis-related protein pathway $p 53 / \mathrm{Bcl}-2 / \mathrm{Cyt}-\mathrm{C} / \mathrm{cas}-$ pase-3.

\section{Discussion}

Hepatocellular carcinoma (HCC) is one of the most common malignant tumors in the clinic, its incidence ranks $6^{\text {th }}$ and mortality ranks $2^{\text {nd }}$ among systemic malignancies. It is becoming the second leading cause of cancer deaths 
TABLE 1: Chemical components identified in the compound.

\begin{tabular}{|c|c|c|c|c|c|}
\hline No. & $\mathrm{tR}$ & MS & Formula & Name & Source \\
\hline 1 & 4.108 & $117.0182[\mathrm{M}-\mathrm{H}]^{-}$ & $\mathrm{C}_{4} \mathrm{H}_{6} \mathrm{O}_{4}$ & Succinic acid & $\mathrm{CR}$ \\
\hline 2 & 6.942 & $179.0164[\mathrm{M}-\mathrm{H}]^{-}$ & $\mathrm{C}_{9} \mathrm{H}_{8} \mathrm{O}_{4}$ & Caffeic acid & $\mathrm{CR}, \mathrm{AR}, \mathrm{HH}, \mathrm{AP}, \mathrm{SC}$ \\
\hline 3 & 7.237 & $353.0888[\mathrm{M}-\mathrm{H}]^{-}$ & $\mathrm{C}_{16} \mathrm{H}_{18} \mathrm{O}_{9}$ & 3-Caffeoylquinic acid & $\mathrm{HH}, \mathrm{SC}$ \\
\hline 4 & 7.284 & $353.0886[\mathrm{M}-\mathrm{H}]^{-}$ & $\mathrm{C}_{16} \mathrm{H}_{18} \mathrm{O}_{9}$ & Chlorogenic acid & $\mathrm{HH}, \mathrm{SC}, \mathrm{SB}$ \\
\hline 5 & 8.425 & $433.0949[\mathrm{M}-\mathrm{H}]^{-}$ & $\mathrm{C}_{20} \mathrm{H}_{18} \mathrm{O}_{11}$ & Quercetin3-O- $\alpha-L$-arabinopyranside & $\mathrm{HH}$ \\
\hline 6 & 12.026 & $685.2349[\mathrm{M}-\mathrm{H}]^{-}$ & $\mathrm{C}_{31} \mathrm{H}_{42} \mathrm{O}_{17}$ & Nuezhenide & $\mathrm{FL}$ \\
\hline 7 & 12.342 & $435.1227[\mathrm{M}-\mathrm{H}]^{-}$ & $\mathrm{C}_{20} \mathrm{H}_{20} \mathrm{O}_{11}$ & Taxifolin $3-O-\beta$-D-xylopyranoside & $\mathrm{AP}$ \\
\hline 8 & 13.609 & $447.0847[\mathrm{M}-\mathrm{H}]^{-}$ & $\mathrm{C}_{21} \mathrm{H}_{20} \mathrm{O}_{11}$ & Quercetin & $\mathrm{HH}$ \\
\hline 9 & 13.942 & $445.0683[\mathrm{M}-\mathrm{H}]^{-}$ & $\mathrm{C}_{22} \mathrm{H}_{22} \mathrm{O}_{10}$ & Calycosin-7-O- $\beta$-D-glucoside & $\mathrm{AR}$ \\
\hline 10 & 19.110 & $407.1319[\mathrm{M}-\mathrm{H}]^{-}$ & $\mathrm{C}_{20} \mathrm{H}_{24} \mathrm{O}_{9}$ & Torachryson-8-O-glucoside & RJ \\
\hline 11 & 20.493 & $431.0951[\mathrm{M}-\mathrm{H}]^{-}$ & $\mathrm{C}_{21} \mathrm{H}_{20} \mathrm{O}_{10}$ & Apigetrin & $\mathrm{AR}$ \\
\hline 12 & 22.510 & $285.0378[\mathrm{M}-\mathrm{H}]^{-}$ & $\mathrm{C}_{15} \mathrm{H}_{10} \mathrm{O}_{6}$ & Luteolin & SB \\
\hline 13 & 27.361 & $283.0594[\mathrm{M}-\mathrm{H}]^{-}$ & $\mathrm{C}_{15} \mathrm{H}_{8} \mathrm{O}_{6}$ & Dihydrokaempferol & SC \\
\hline 14 & 30.545 & $269.0442[\mathrm{M}-\mathrm{H}]^{-}$ & $\mathrm{C}_{15} \mathrm{H}_{10} \mathrm{O}_{5}$ & Apigenin & SB \\
\hline 15 & 43.063 & $253.1067[\mathrm{M}-\mathrm{H}]^{-}$ & $\mathrm{C}_{16} \mathrm{H}_{14} \mathrm{O}_{3}$ & 6-Methoxyflavanone & $\mathrm{HH}$ \\
\hline 16 & 46.180 & $237.0540[\mathrm{M}-\mathrm{H}]^{-}$ & $\mathrm{C}_{15} \mathrm{H}_{10} \mathrm{O}_{3}$ & 2-Methyl-3-hydroxyanthraquinone & $\mathrm{HH}$ \\
\hline 17 & 52.097 & $293.2107[\mathrm{M}-\mathrm{H}]^{-}$ & $\mathrm{C}_{18} \mathrm{H}_{30} \mathrm{O}_{3}$ & 9,10-Epoxy-10,12-octadecadienoic acid & CR \\
\hline 18 & 53.514 & $269.0444[\mathrm{M}-\mathrm{H}]^{-}$ & $\mathrm{C}_{15} \mathrm{H}_{10} \mathrm{O}_{5}$ & Aloe emodin & $\mathrm{RJ}$ \\
\hline 19 & 55.481 & $295.2260[\mathrm{M}-\mathrm{H}]^{-}$ & $\mathrm{C}_{18} \mathrm{H}_{32} \mathrm{O}_{3}$ & 9,10-Epoxy-12-octadecenoic acid & $\mathrm{CR}$ \\
\hline
\end{tabular}

SB: Scutellaria barbata D. Don; RJ: Reynoutria japonica Houtt; SC: Smilax china L.; FL: Fructus Ligustri Lucidi; CR: Codonopsis Radix; AR: Astragali Radix; HH: Herba Hedyotidis Diffusae; AP: Agrimonia pilosa Ledeb.

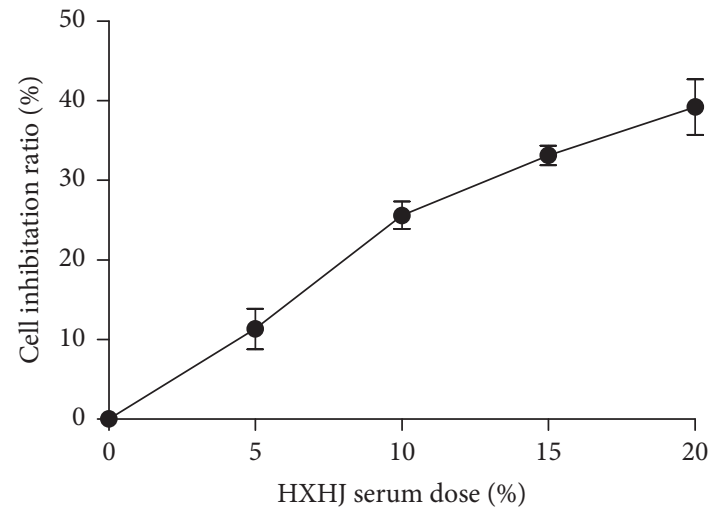

(a)

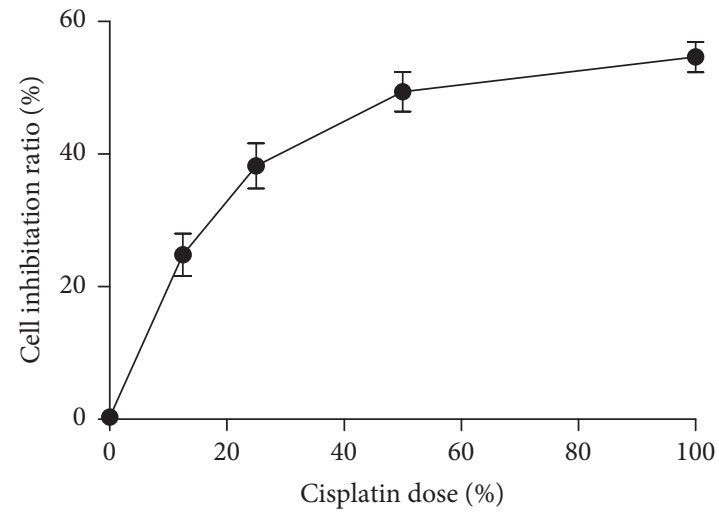

(b)

FIGURE 2: Continued. 


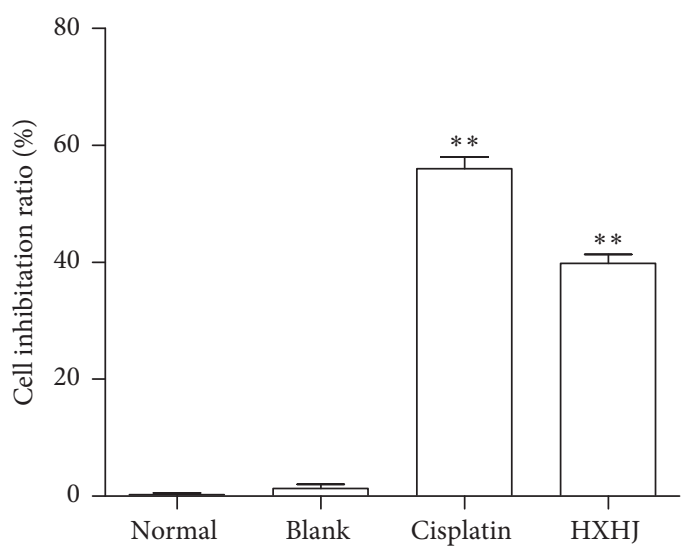

(c)

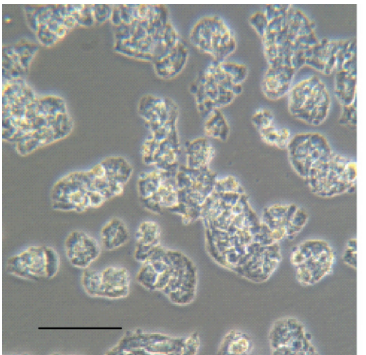

Normal

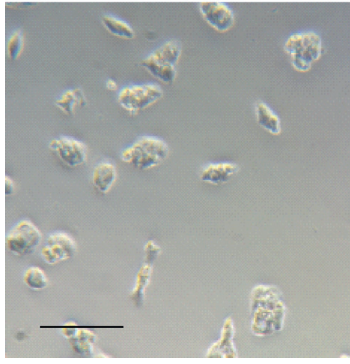

Cisplatin

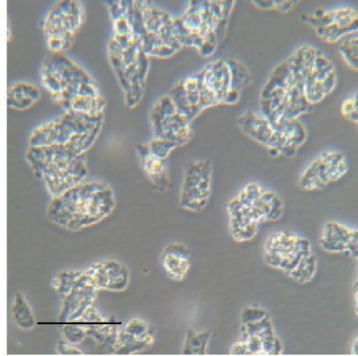

Blank

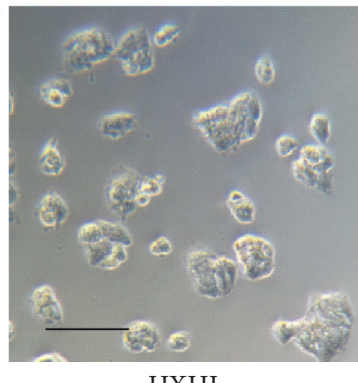

HXHJ

(d)

FIgURE 2: HXHJ-medicated serum induced HepG2 cell proliferation inhibition and morphological changes. (a) CCK8 determination. The cells were treated with different percentages of HXHJ-medicated serum to obtain the corresponding cell inhibition rate (mean \pm SD). (b) $20 \% \mathrm{HXHJ}$-medicated serum inhibits the proliferation of HepG2 cells and (c) influences cell morphology under an inverted microscope. ${ }^{* *} p<0.01$ versus blank group. Data, mean $\pm \mathrm{SD}(n=3$, bar $=50 \mu \mathrm{m}, \times 100)$.
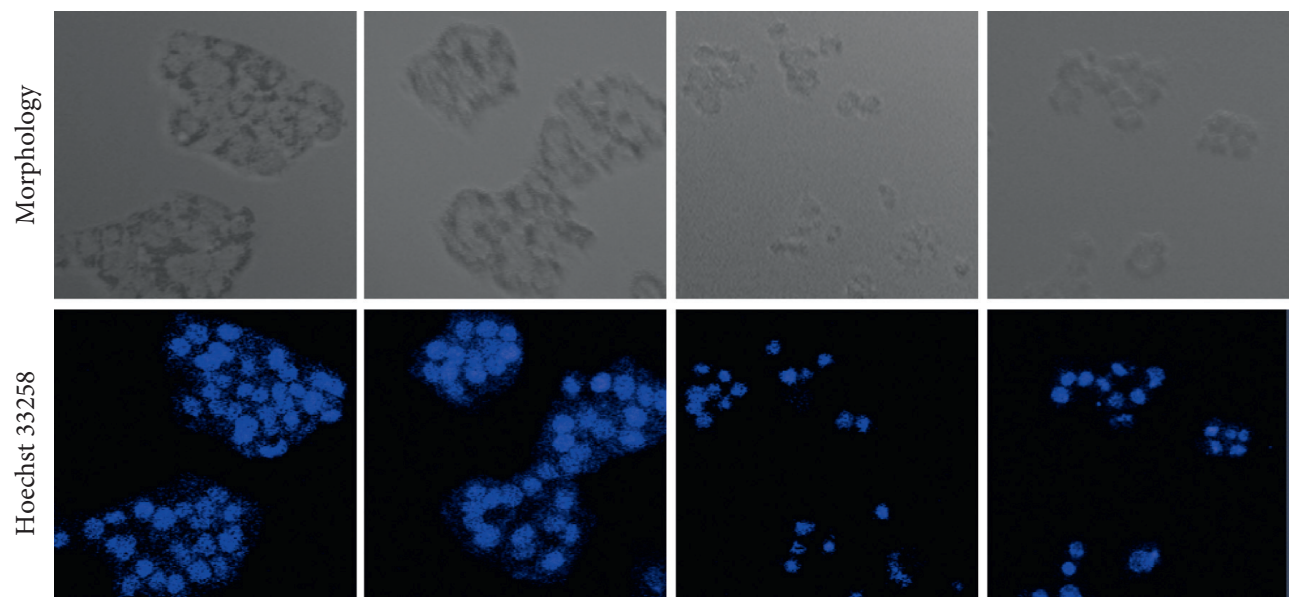

(a)

Figure 3: Continued. 

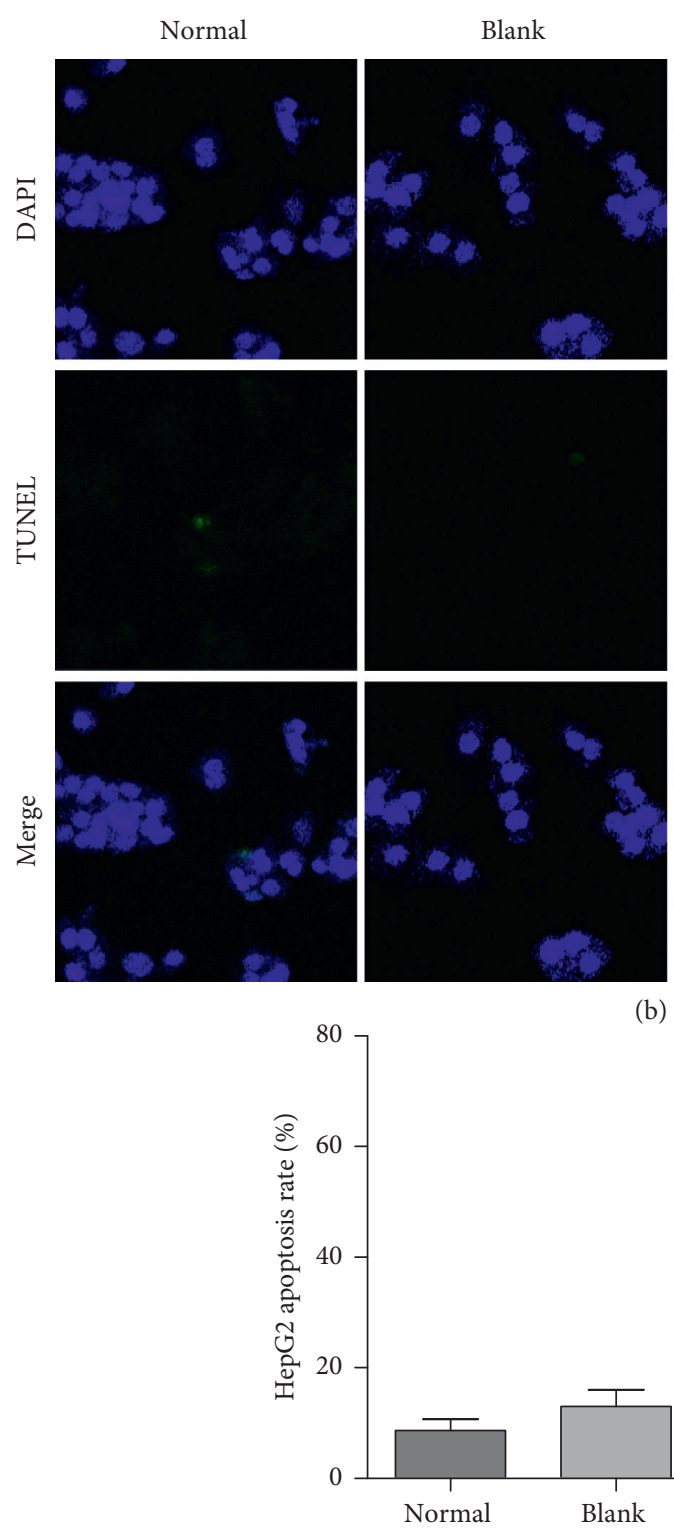

(b)

)
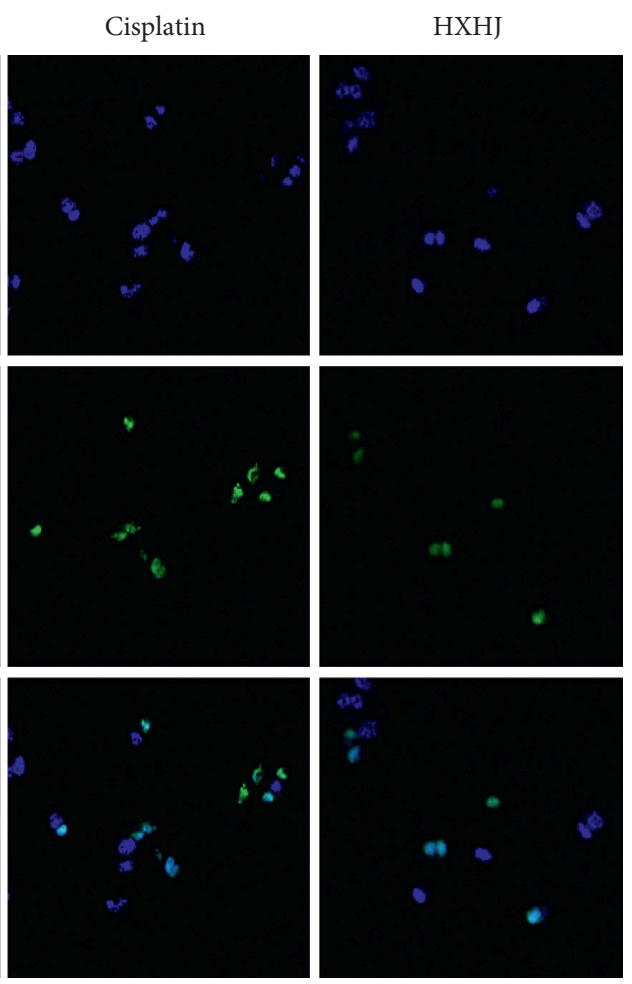


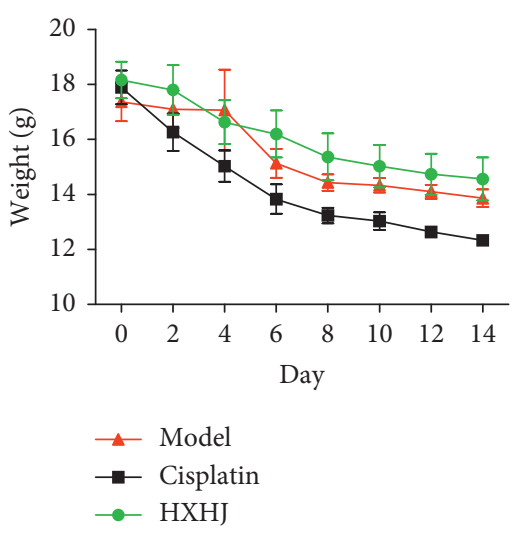

(a)

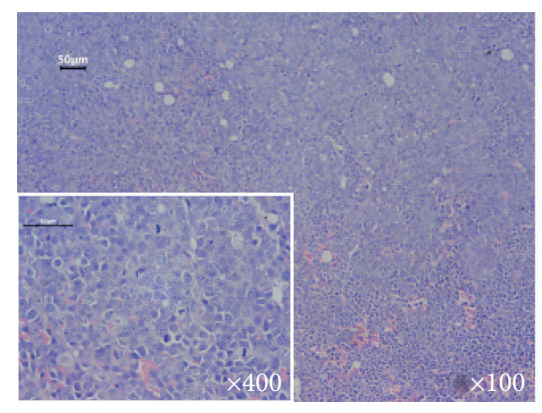

Model

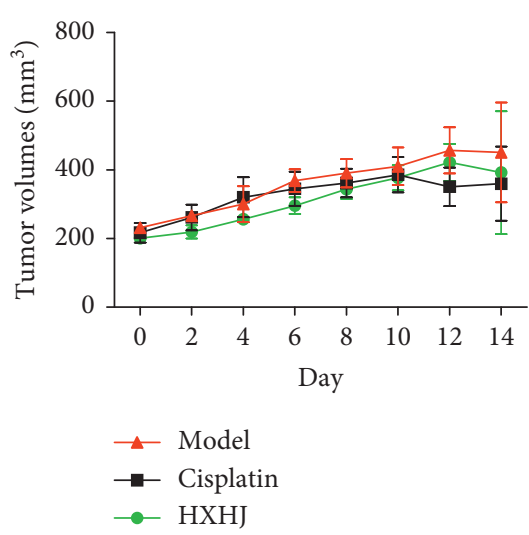

(b)

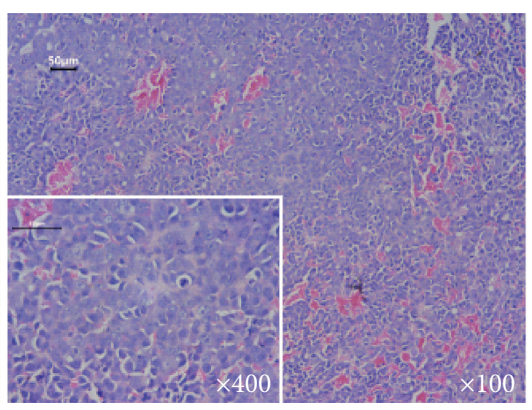

Cisplatin

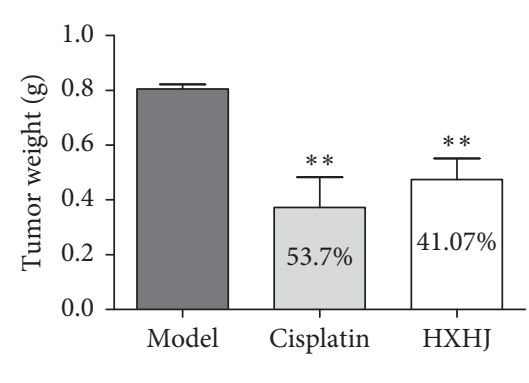

(c)

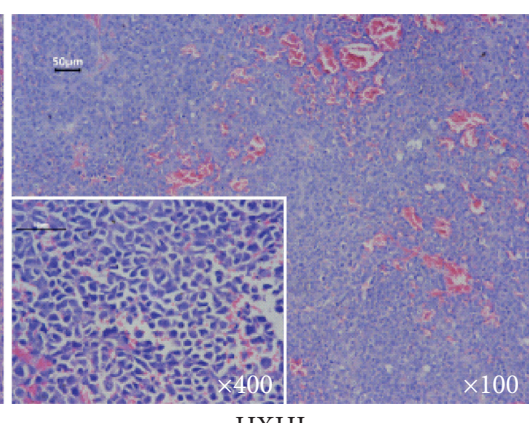

HXHJ

(d)

FIgURE 4: HXHJ inhibits tumor growth of HepG2 xenograft tumor in nude mice. (a) Comparison of the body mass of nude mice with HepG2 xenograft tumors in each group. (b) Tumor volume change. (c) Tumor weight and tumor inhibition rate. Data, mean \pm SD, $n=6$, ${ }^{* *} p<0.01$, versus model group. (d) HE staining. Observe the morphological changes of tumor tissue cells $(n=3$, scale $=50 \mu \mathrm{m}, \times 100, \times 400)$.

relieve clinical symptoms, delay tumor progression, and improve the quality of life of patients [20]. Modern studies have shown that $[21,22]$ Astragalus has a good effect of inhibiting the growth and promoting apoptosis of cancer cells. Huanglian Jiedu decoction and its constituent herbs have a good therapeutic effect on HCC, can effectively induce cancer cell cycle arrest, and attenuate the expression of the antiapoptotic protein $\mathrm{Bcl}-\mathrm{x}$ in HepG2 cells. The traditional Chinese medicine compound preparation Huxie Huaji (HXHJ) Ointment used in this study is a clinically proven prescription based on the basic pathogenesis of "deficiency, blood stasis, and toxin" in Traditional Chinese Medicine, through the combination of symptoms and precise compatibility. The prescription adjuvant clinical chemotherapy and single administration have a significant curative effect on liver cancer, and long-term use has a few side effects, but the mechanism of action is not clear.

Previous studies have found that HXHJ could significantly inhibit the proliferation of liver cancer cells $\mathrm{H}_{22}$, induce the imbalance of the expression ratio of Bax and Bcl-2 proteins in the cells, and promote the apoptosis of cancer cells [11]. In order to further clarify the curative effect of $\mathrm{HXHJ}$ against HCC, we used the CCK8 method to analyze and evaluate the viability of HepG2 cells and found that $20 \%$ of HXHJ-containing serum has a good inhibitory effect on the proliferation of HepG2 cells in in vitro studies. At the same time, through the double verification of Hoechst and TUNEL staining methods, the above-mentioned inhibition of HepG2 cell proliferation may be closely related to the induction of cell apoptosis. In vivo experiments have also proved that HXHJ could effectively inhibit the growth of xenotransplanted HepG2 cell nude mice tumors and induce tumor cell rupture and apoptosis.

Mitochondria play a central and multifunctional role in the proliferation and growth of malignant tumor cells; the reduction of membrane potential and the release of proapoptotic proteins are important links in causing cell apoptosis [23]. In previous studies, it was found that the tumor suppressor gene $p 53$ in liver cancer patients was obviously lost or mutated, and cancer cell apoptosis was significantly inhibited $[24,25] . p 53$ is the most common mutated gene in human cancers, can initiate various cell responses, and can cause cell cycle arrest and apoptosis, which plays an important role in the mitochondrial apoptotic pathway, and its activation can directly induce the expression of the proapoptotic protein Bax [26]. Bax, located on the cell mitochondrial membrane, is an important member of the Bcl-2 family and the main protein that regulates cell apoptosis and has become an important drug target [27]. Under the stimulation of the apoptotic signal p53, Bax can form a transmembrane channel or activate mitochondrial PT pores on the outer mitochondrial membrane through 

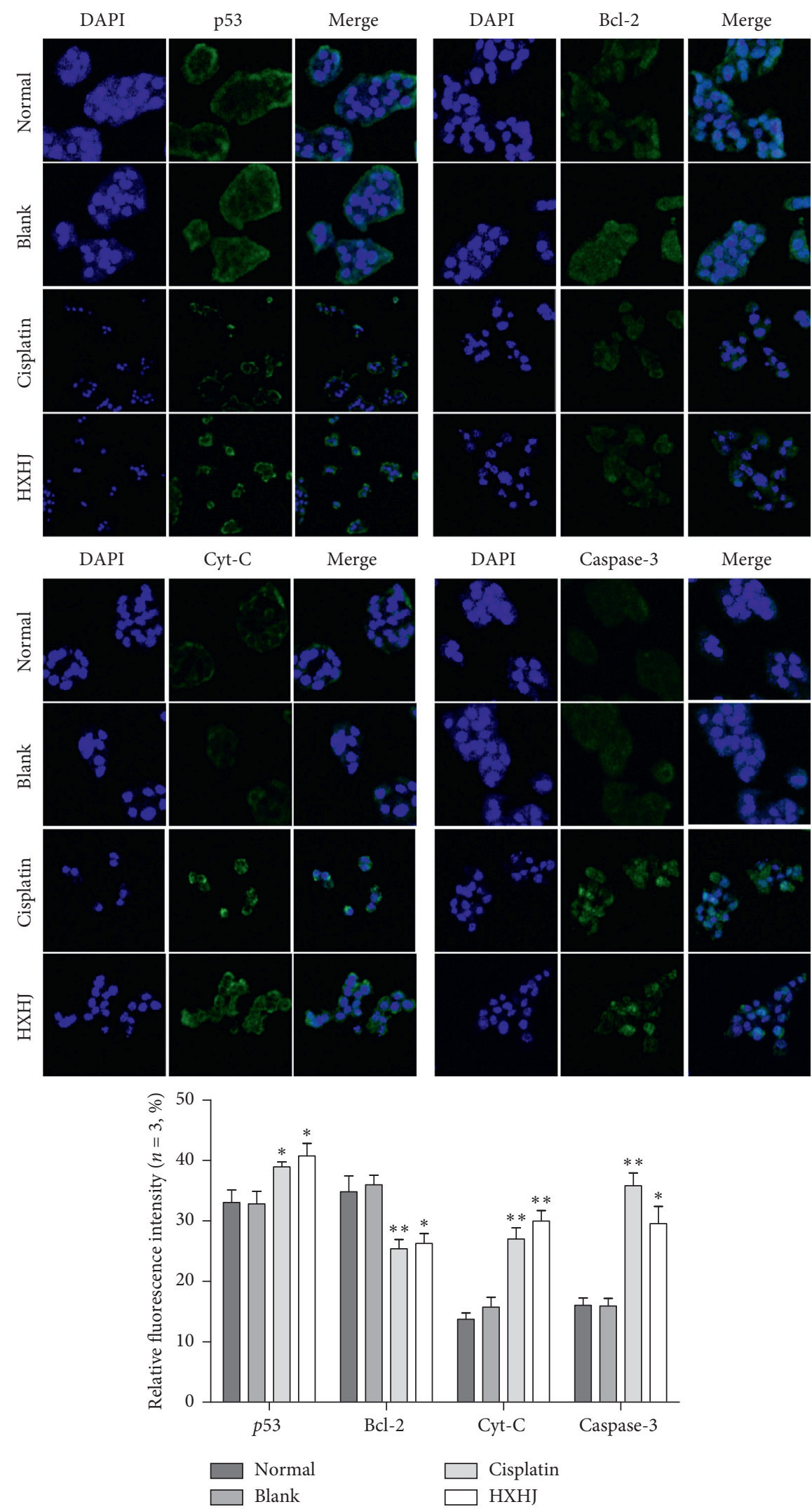

(a)

Figure 5: Continued. 


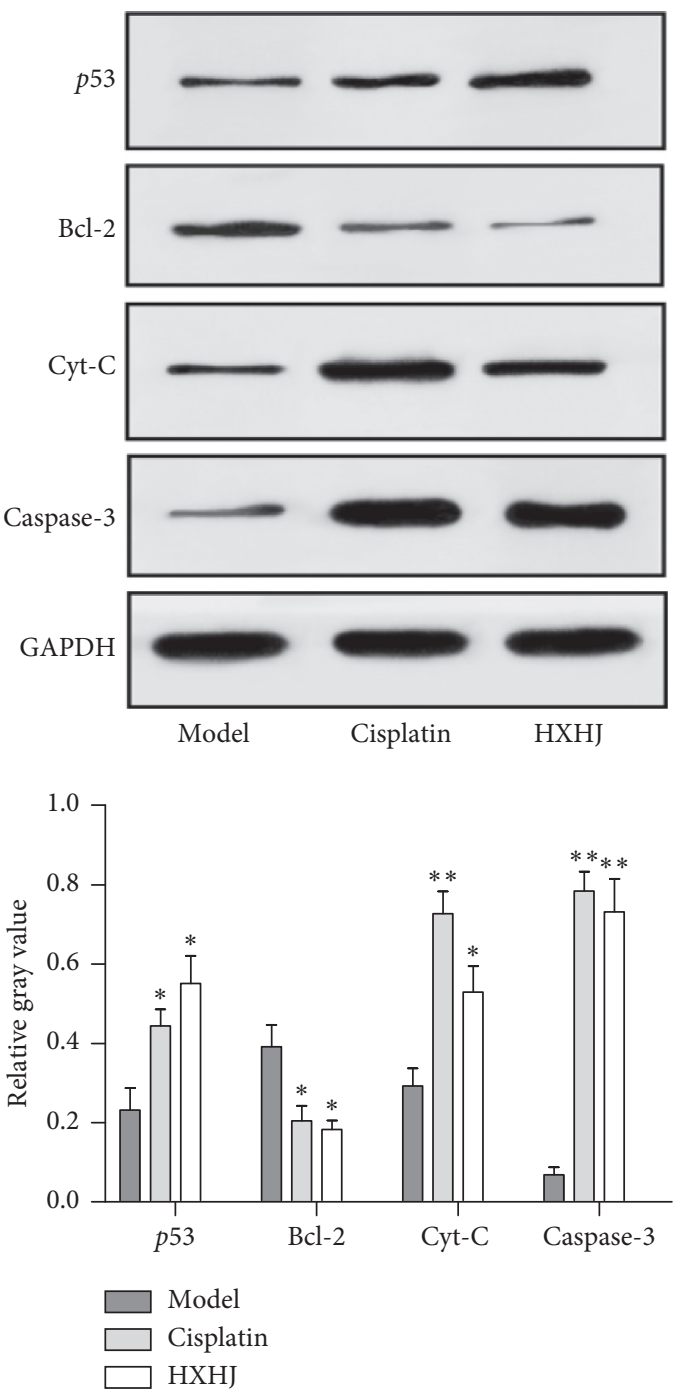

(b)

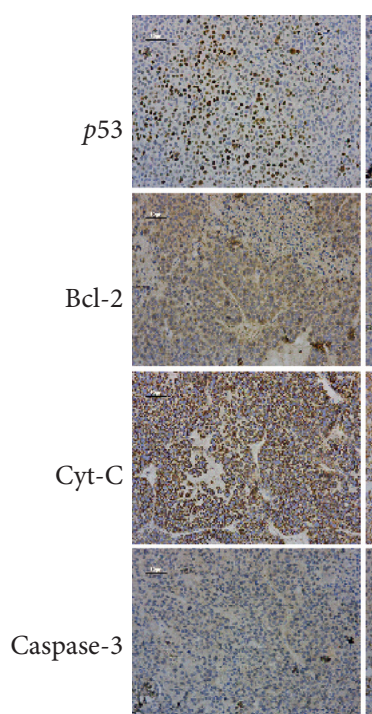

Model

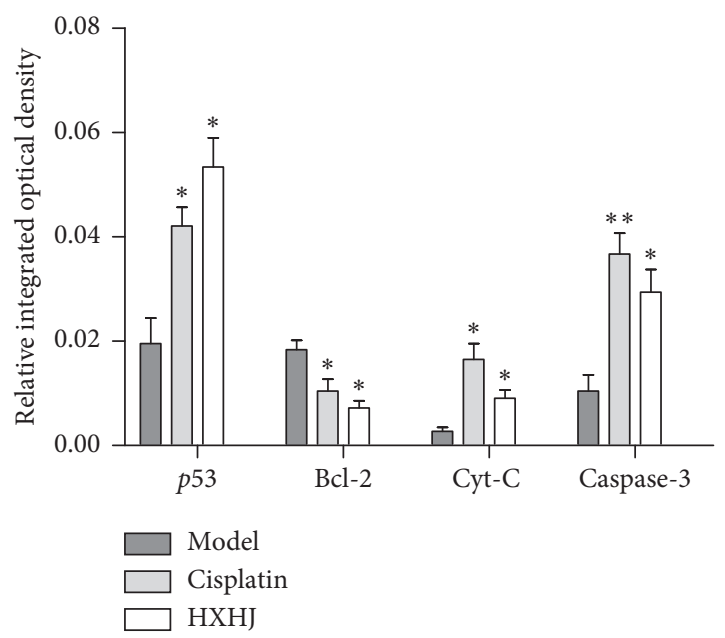

(c)

FIGURE 5: HXHJ regulated the expression of $p 53 / \mathrm{Bcl}-2 / \mathrm{Cyt}-\mathrm{C} / \mathrm{caspase}-3$ in vivo and in vitro. (a) Immunofluorescence. Observe the protein fluorescence intensity under a laser confocal microscope and use the average cell fluorescence intensity value to reflect the relative expression level of each protein $(\times 400)$. Data, mean $\pm \mathrm{SD}, n=3 .{ }^{*} p<0.05,{ }^{* *} p<0.01$, versus blank. (b) Western blotting. Image J software was used to analyze and process protein gray-scale bands. (c) Immunohistochemistry. Observe and count the integral optical density value of protein under a biological imaging microscope $(\times 400)$. p53: tumor suppressor protein. Bcl-2: B-cell lymphoma 2 gene. Cyt-C: apoptosis-related protein cytochrome $\mathrm{C}$; caspase-3: aspartate proteolytic enzyme-3. Data, mean $\pm \mathrm{SD}, n=3 .{ }^{*} p<0.05,{ }^{* *} p<0.01$, versus model.

oligomerization, the integrity of the membrane was reduced, the membrane potential was decreased or lost, and apoptosis was increased [28]. The antiapoptotic protein Bcl-2 hindered the flow of $\mathrm{Ca}^{2+}$ from the endoplasmic reticulum to the cytoplasm and combined with Bax to form a Bax-Bcl-2 heterodimer, thereby preventing the occurrence of cell apoptosis [29]. On the one hand, the imbalance of the Bax/ $\mathrm{Bcl}-2$ ratio formed a large number of Bax-Bax homodimers to promote the permeabilization of the mitochondrial membrane; on the other hand, it induced the release of the apoptotic factor cytochrome C (Cyt-C) [30]. A large amount of Cyt-C was compounded with caspase- 9 and apoptotic enzyme activator Apaf-1 to form apoptotic bodies, which triggered the self-activation of caspase 9, then activated the apoptotic executive protein caspase-3 and caspase-dependent nucleases, and promoted the increase of cell apoptosis [31, 32].

In order to further explore the mechanism of $\mathrm{HXHJ}$ inducing apoptosis of HCC cells, our study combined in vivo and in vitro experiments; used immunofluorescence, western blot, and other methods; and found that HXHJ may regulate the expression of tumor cell signaling pathway $p 53 /$ Bcl-2/Cyt-C/caspase-3, which induced mitochondrial cell apoptosis, thereby exerting a good anti-HCC effect. 3-Kinase/protein kinase $\mathrm{B}$ (PI3K/Akt) and mitogen-activated protein kinases (MAPKs) are also regulated by mitochondrial signaling [33]. In addition, the apoptotic pathway is not only related to the mitochondrial apoptotic pathway but also 
related to the death receptor pathway, mainly by recruiting the Fas-related death domain (FADD) adaptor protein and activating the procaspase- 2 precursor to start the cell apoptosis [34]. Chinese herbal medicine has unique multipathway and multitarget regulation characteristics. Whether the anti-HCC effect of our HXHJ is also related to the regulation of the above-mentioned signal pathways needs to be further explored.

\section{Conclusions}

HXHJ Ointment had a significant effect on promoting apoptosis of tumor cells. The mechanism may be related to activating the $p 53 / \mathrm{Bcl}-2 / \mathrm{Cyt}-\mathrm{C} /$ caspase- 3 signaling pathway and inducing mitochondrial cell apoptosis.

\section{Abbreviations}

\section{HXHJ: Huxie Huaji Ointment}

HCC: Hepatocellular carcinoma

Bcl-2: B-cell lymphoma 2 gene

Cyt-C: Cytochrome C

H\&E: Hematoxylin and eosin

TCM: Traditional Chinese medicine

TCMF: Traditional Chinese medicine formulas.

\section{Data Availability}

The data used to support the findings of this study are included within the article.

\section{Conflicts of Interest}

The authors declare no conflicts of interest.

\section{Authors' Contributions}

PHZ and SRY designed the experiments, supervised, and participated in the entire work. Y C and Q D maintained and performed cell and animal studies, wrote the manuscript, and revised the manuscript. BBS was in charge of statistical analysis. DTH participated in study design and data collection. All the authors revised and approved the final manuscript. Yuan Cai and Qing Du contributed equally to this work.

\section{Acknowledgments}

This work was supported by the National Natural Science Youth Fund Project (no. 81503197), Hunan Natural Science Youth Fund Project (no. 2018JJ3310 and 2019JJ50345), Hunan Provincial Traditional Chinese Medicine Administration Project (no. 201810), and the project of Natural Science Foundation of Jiangxi Province (no. 20171BAB205080).

\section{References}

[1] C. P. Wild, E. Weiderpass, and B. W. Stewart, World Cancer Report: Cancer Research for Cancer Prevention, WHO, Geneva, Switzerland, 2020.
[2] J. Armendáriz-Borunda, M. Galicia-Moreno, M. CamposValdez, H. C. Monroy-Ramírez, and H. Research, "Hepatocellular carcinoma and hepatitis $\mathrm{C}$ virus infection in Latin America: epidemiology, diagnosis and treatment," Hepatoma Research, vol. 6, 2020.

[3] M. Yarchoan, P. Agarwal, A. Villanueva et al., "Recent developments and therapeutic strategies against hepatocellular carcinoma," Cancer Research, vol. 79, no. 17, pp. 4326-4330, 2019.

[4] D. D. Aufhauser, E. Sadot, D. R. Murken et al., "Incidence of occult intrahepatic metastasis in hepatocellular carcinoma treated with transplantation corresponds to early recurrence rates after partial hepatectomy," Annals of Surgery, vol. 267, pp. 922-928, 2018.

[5] Y. Hu, S. Wang, X. Wu et al., "Chinese herbal medicinederived compounds for cancer therapy: a focus on hepatocellular carcinoma," Journal of Ethnopharmacology, vol. 149, no. 3, pp. 601-612, 2013.

[6] S. Y. Xi and G. Y. Minuk, "Role of traditional Chinese medicine in the management of patients with hepatocellular carcinoma," World Journal of Hepatology, vol. 10, pp. 799806, 2018.

[7] Y. Deng, X. Li, X. Li et al., "Corilagin induces the apoptosis of hepatocellular carcinoma cells through the mitochondrial apoptotic and death receptor pathways," Oncology Reports, vol. 39, pp. 2545-2552, 2018.

[8] S. Zheng, "Mitochondrial dysfunction-related genes in hepatocellular carcinoma," Frontiers in Bioscience, vol. 18, no. 3, pp. 1141-1149, 2013.

[9] J. Estaquier, F. Vallette, J.-L. Vayssiere, and B. Mignotte, “The mitochondrial pathways of apoptosis," Advances in Experimental Medicine and Biology, vol. 942, pp. 157-183, 2012.

[10] C. Zheng, T. Liu, H. Liu, and J. Wang, "BCL-2 family proteins in apoptosis and its regulation," Current Protein \& Peptide Science, vol. 21, no. 8, 2019.

[11] D. Qing, C. Yuan, S. Bing-Bing, L. Xin Liang, X. Fang Yi, and Z. Shui Han, "Effect and mechanism of Huxie Huaji ointment combined with cisplatin on apoptosis of $\mathrm{H}_{22}$ cells of liver cancer," Journal of Beijing University of Traditional Chinese Medicine, vol. 42, pp. 409-415, 2019.

[12] E. G. Lim, G. T. Kim, B. M. Kim et al., "Ethanol extract from Cnidium monnieri (L.) cusson induces cell cycle arrest and apoptosis via regulation of the p53-independent pathway in HepG2 and Hep3B hepatocellular carcinoma cells," Molecular Medicine Reports, vol. 17, no. 2, 2018.

[13] W. A. Chao, A. Wc, F. A. Meng et al., "Compound astragalus and Salvia miltiorrhiza extract inhibits hepatocellular carcinoma progression via miR-145/miR-21 mediated Smad3 phosphorylation," Journal of Ethnopharmacology, vol. 231, pp. 98-112, 2019.

[14] M. F. Chedid, C. R. P. Kruel, M. A. Pinto et al., "Hepatocellular carcinoma: diagnosis and operative management," ABCD. Arquivos Brasileiros de Cirurgia Digestiva (São Paulo), vol. 30, no. 4, pp. 272-278, 2017.

[15] C. He, T Wu, and Y. Hao, "Anlotinib induces hepatocellular carcinoma apoptosis and inhibits proliferation via Erk and Akt pathway," Biochemical and Biophysical Research Communications, vol. 503, pp. 3093-3099, 2018.

[16] X. Chao, G. Wang, Y. Tang et al., "The effects and mechanism of peiminine-induced apoptosis in human hepatocellular carcinoma HepG2 cells," PLoS One, vol. 14, Article ID e0201864, 2019.

[17] L.-Y. Kuan, W.-L. Chen, J.-H. Chen et al., "Magnolol induces apoptosis and inhibits ERK-modulated metastatic potential in 
hepatocellular carcinoma cells," In Vivo, vol. 32, no. 6, pp. 1361-1368, 2018.

[18] F. T. Hsu, Y. C. Liu, I. T. Chiang et al., "Sorafenib increases efficacy of vorinostat against human hepatocellular carcinoma through transduction inhibition of vorinostat-induced ERK/ NF- $\kappa$ B signaling," International Journal of Oncology, vol. 45, no. 1, pp. 177-188, 2014.

[19] M. C. Weng, M. H. Wang, J. J. Tsai et al., "Regorafenib inhibits tumor progression through suppression of ERK/NF- $\kappa \mathrm{B}$ activation in hepatocellular carcinoma bearing mice," Bioscience Reports, vol. 38, no. 3, Article ID BRS, 2018.

[20] B. Hu, W. Shuang-Shuang, and D. Qin, "Traditional Chinese medicine for prevention and treatment of hepatocarcinoma: from bench to bedside," World Journal of Hepatology, vol. 7, no. 9, pp. 1209-1232, 2015.

[21] S. R. Chen, H. C. Qiu, Y. Hu, Y. Wang, and Y. T. Wang, "Herbal medicine offered as an initiative therapeutic option for the management of hepatocellular carcinoma," Phytotherapy Research, vol. 30, no. 6, pp. 863-877, 2016.

[22] Z. Wen Hua, B. Hua, H. Xian Zhang et al., "Traditional Chinese medicine (TCM) astragalus membranaceus and curcuma wenyujin promote vascular normalization in tumorderived endothelial cells of human hepatocellular carcinoma," Anticancer Research, vol. 39, pp. 2739-2747, 2019.

[23] M. V. Jain, A. M. Paczulla, T. Klonisch et al., "Interconnections between apoptotic, autophagic and necrotic pathways: implications for cancer therapy development," Journal of Cellular and Molecular Medicine, vol. 17, no. 1, pp. 12-29, 2013.

[24] A. F. Brito, A. M. Abrantes, C. Pinto-Costa et al., "Hepatocellular carcinoma and chemotherapy: the role of $p 53$," Chemotherapy, vol. 58, no. 5, pp. 381-386, 2012.

[25] W. Zheng, H. J. Yu, X. G. Dong et al., "Critical roles of $p 53$ in epithelial-mesenchymal transition and metastasis of hepatocellular carcinoma cells," PLoS One, vol. 8, Article ID e72846, 2013.

[26] L. Bi, X. Yan, W. Chen, J. Gao, L. Qian, and S. Qiu, “Antihepatocellular carcinoma potential of tetramethylpyrazine induces cell cycle modulation and mitochondrial-dependent apoptosis: regulation of $p 53$ signaling pathway in HepG2 cells in vitro," Integrative Cancer Therapies, vol. 15, no. 2, pp. 226-236, 2016.

[27] K. Qiang, Z. Hao, Y. Xuan et al., "Characterization and prognostic significance of mortalin, Bcl-2 and Bax in intrahepatic cholangiocarcinoma," Oncology Letters, vol. 15, no. 2, pp. 2161-2168, 2017.

[28] X. Xu, Y. Lai, and Z. C. Hua, “Apoptosis and apoptotic body: disease message and therapeutic target potentials," Bioscience Reports, vol. 39, no. 1, Article ID BRS20180992, 2018.

[29] N. Ueda, "Ceramide-induced apoptosis in renal tubular cells: a role of mitochondria and sphingosine-1-phoshate," International Journal of Molecular Sciences, vol. 16, no. 12, pp. 5076-5124, 2015.

[30] D. C. Phillips, S. Martin, B. T. Doyle, and J. A. Houghton, "Sphingosine-induced apoptosis in rhabdomyosarcoma cell lines is dependent on pre-mitochondrial bax activation and post-mitochondrial caspases," Cancer Research, vol. 67, no. 2, pp. 756-764, 2007.

[31] Z. Liu, Y. Ding, N. Ye, C. Wild, H. Chen, and J. Zhou, "Direct activation of Bax protein for cancer therapy," Medicinal Research Reviews, vol. 36, pp. 313-341, 2016.

[32] S. Yu-Chi, D. G. V. Naga, C. Cheng-Hao et al., "Galectin-1induced autophagy facilitates cisplatin resistance of hepatocellular carcinoma," PLoS One, vol. 11, no. 2, Article ID e0148408, 2016.

[33] Z. Liu, B. Ren, Y. Wang et al., "Sesamol induces human hepatocellular carcinoma cells apoptosis by impairing mitochondrial function and suppressing autophagy," Scientific Reports, vol. 7, Article ID 45728, 2017.

[34] Z. Qiao, Y. Cheng, S. Liu, Z. Ma, S. Li, and W. Zhang, "Casticin inhibits esophageal cancer cell proliferation and promotes apoptosis by regulating mitochondrial apoptotic and JNK signaling pathways," Naunyn-Schmiedeberg's Archives of Pharmacology, vol. 392, no. 2, pp. 177-187, 2019. 